\title{
Confinamento e cuidado: a suspensão no mundo da técnica como condição para a liberdade
}

\author{
Confinement and care: the suspensions in the world of technic as a condition for \\ freedom
}

\begin{abstract}
Alex Antônio Rosa Costa*
Resumo: Este ensaio pretende analisar a situação atual de confinamento imposta pela pandemia de Covid-19 a partir dos conceitos heideggerianos de técnica, quotidiano e preocupação. Defendemos que o isolamento oferece as condições materiais para que mais pessoas deem atenção a si mesmas e cuidem de si mesmas, do que resulta um deixar-ser tanto a própria liberdade quanto a do outro. Com isso, as possibilidades que somos são encaradas como tais, em especial nosso ser-para-a-morte.

Palavras-chave: Heidegger; Cuidado; Quotidiano; Possibilidades; Covid-19

Abstract: This essay aims at analyzing the current situation of confinement imposed by the Covid-19 pandemic from the Heideggerian concepts of technic, every day, and care. We defend that the isolation offers the material conditions to more people pay attention to themselves and take care of themselves, resulting in letting-be the freedom of oneself and of the other. Therefore, we face the possibilities which we are as such, especially our being-toward-Death.

Keywords: Heidegger; Care; Every day; Possibilities; Covid-19
\end{abstract}

\section{Introdução}

Em 22 de junho de 1925, o já professor universitário Martin Heidegger escreveu para sua jovem aluna de graduação Hannah Arendt, à época com 18 anos, por quem estava perdidamente apaixonado:

Agimos apenas na medida em que podemos dar - se o que é dado é sempre igual, ou se em geral é aceito, dá no mesmo. E nós apenas temos direito de ser na medida em que somos capazes de dar atenção, pois nós apenas podemos dar aquilo que de nós mesmos exigimos. E unicamente a profundidade na qual eu posso exigir, de mim mesmo, o meu ser decide sobre meu ser para os outros ${ }^{1}$.

O estilo enigmático heideggeriano está sempre presente, até mesmo em suas cartas pessoais. Aqui, podemos começar do mais evidente. Heidegger defende para sua aluna a importância de darmos atenção. A quê? Ao que é. O filósofo tem em mente aqui, creio, uma crítica ao mais comum modo de se viver e pensar, tanto entre os filósofos quanto entre as pessoas de maneira geral: um modo que se distancia do ser. Lembremos que Heidegger caracteriza a história da metafísica, isto é, a história da filosofia europeia desde Platão, como a história do esquecimento do ser. Para o alemão, os filósofos gregos começaram a elaborar

\footnotetext{
1 "Wir wirken nur soweit, als wir zu geben vermögen — ob die Gabe immer gleich, oder überhaupt genommen wird, ist gleichgültig. Und wir haben nur soviel Recht zu sein, als wir es vermögen, achtzugeben. Denn wir selbst können nur geben, was wir von uns selbst uns abverlangen. Und einzig die Tiefe, in der ich von mir selbst mein Sein verlangen kann, entscheidet über mein Sein zu anderen" (ARENDT, Briefe 1925 bis 1975: und andere Zeugnisse, 37) (tradução livre)
} 
pela primeira vez a pergunta mais importante - se não a única - da filosofia: a pergunta pelo ser. 0 auge do questionamento foi com Platão e Aristóteles, ocorrendo, depois, apenas o distanciamento da questão fundamental da humanidade. Junto com Nietzsche ${ }^{2}$, o qual é reconhecido como o último pensador metafísico ocidental, Heidegger encara a história europeia como a história da degeneração, sendo o século XX o cume, o fim dos tempos. Isso se dá, entre outros aspectos, pelo que o alemão chamará de "predomínio do mundo da técnica". Vivemos no mundo da técnica, um mundo em que toda a nossa atenção está voltada exclusivamente para o desenvolvimento técnico-científico, em que o importante é o que patrocina o progresso ${ }^{3}$. 0 resultado desse modo de viver e pensar é o total esquecimento da pergunta fundamental, o que engloba a pergunta pelo ser do homem. 0 mundo da técnica (apenas imagine o que Heidegger diria de nossos dias! - a maior invenção tecnológica que ele viu no quotidiano foi a televisão) engole todo o verdadeiro pensamento, toda a reflexão, para fomentar apenas o pensamento calculista e utilitarista. Nossa atenção está no lugar errado. Assim, ao falar de dar atenção, Heidegger parece indicar o fato de estarmos num mundo em que a atenção verdadeira foi esquecida. Toda a nossa capacidade de pensamento - e isso é o mesmo que a nossa capacidade de olhar retamente para as coisas mesmas ${ }^{4}$, ou de darmos a devida atenção às coisas - está hibernada 5 . Qual o problema nisso tudo? Na carta, o filósofo deixou claro: sem darmos atenção, não temos o direito de ser. Com a atenção dispersa na técnica, perdemos nosso direito de ser; em outras palavras, não somos. Isso não quer dizer, é claro, que não existimos; quer dizer: não existimos autenticamente, não somos nós que vivemos nossa vida, mas alguma outra coisa a vive. Veremos adiante o que isso quer dizer.

\section{Século XX, o reinado da técnica e da impessoalidade}

O século XX foi o século da técnica por excelência. Século da internet, da comunicação, século que culminou nas redes sociais e se enterrou com as fake news. 0 século XX, que começou um pouco mais tarde, como defende E. Hobsbawm, agora encontra sua tumba, em 2020. 0 século XXI começa para nós na escuridão. Ainda não sabemos quase nada do que será a semana que vem. 0 avanço da tecnologia parecia já nos ter habituado à incerteza do futuro próximo. A pandemia global nos veio comprovar que o desconhecimento e a imprevisibilidade do futuro ainda podiam aumentar, e muito. Estamos diante de uma grande mudança. Como toda vez que uma alteração estrutural dessa magnitude acontece, qualquer projeção de futuro se mostra insuficiente, ou mesmo impossibilitada. No entanto, devemos procurar compreender as possibilidades oferecidas pela situação em que vivemos - possibilidades que agora se mostram deveras diferentes das que conhecíamos há poucas semanas - a fim não de prever o futuro, mas de tomarmos consciência do que podemos fazer para criar nosso futuro.

Pretenderei compreender neste ensaio algumas das possibilidades que se nos mostram em meio à pandemia de Covid-19 tomando como ponto de partida o trecho da carta de Heidegger de que falamos acima. É bem verdade que a forma com que lidamos com a situação atual e as dificuldades que enfrentamos são bem distintas. Há muitos agoniando de fome, alguns aumentando a renda; alguns sem o que fazer, outros trabalhando muito mais que antes; alguns saudáveis, outros sucumbindo ao vírus. Seria impossível aqui oferecer uma visão que valha para todos. Minha pretensão é muito mais modesta: pretendo apenas oferecer uma pequena contribuição em meio a muito mais que se deve falar.

Embora haja tantas diferenças entre nós, fato é que a atenção de todos foi alterada. Medidas de isolamento sendo impostas em todo o mundo acarretam uma mudança radical no

\footnotetext{
2 Ver, por todos, HEIDEGGER, Nietzsche II, cap. VIII - A metafísica como história do ser.

3 Ver entendimento nietzscheano de progresso em, e.g, Para Além do Bem e do Mal, §201.

${ }^{4}$ Ver HEIDEGGER, $A$ teoria platônica da verdade.

5 Ver HEIDEGGER, Serenidade, 12.
} 
atributo fundamental do homem e da vida médios: a cotidianidade [Alltäglichkeit] ${ }^{6}$, a grande responsável, aos olhos do Heidegger, de uma vida inautêntica, de uma vida distante de nós mesmos, vida que, no século XX, foi marcada pela técnica.

Em sua grande obra, Ser e Tempo, Heidegger nos mostra que a vida quotidiana tolhe do homem seu próprio ser. Perdemos todo o poder sobre nós mesmos em nome de uma vida pronta e impessoal oferecida por A-gente [Das Man] $]^{7}$. Todas as nossas possibilidades, todas as escolhas que podemos fazer de nós mesmos, são perdidas na impessoalidade. Na vida quotidiana, perdemos o eu e o tu, perdemos a individualidade, a subjetividade, para vivermos a vida de a-gente, do neutro. 0 homem médio, o homem quotidiano, tem seu ser neutralizado pelo outro. 0 grande problema aqui é que esse outro não tem rosto, não tem nome, não tem endereço. Seria fácil se colocássemos a culpa da morte do ser (do) humano em alguém. Bastaria decapitá-lo. 0 outro que tira nosso ser de nós, contudo, é um outro que paira em meio a toda a sociedade. É o anônimo por excelência. Escreve Heidegger em um dos trechos mais tristes de Ser e Tempo:

Gozamos e nos satisfazemos como a-gente goza; nos afastamos também da "grande massa" como a-gente se afasta; achamos "escandaloso" o que a-gente acha escandaloso. A-gente, que não é ninguém determinado e que todos são, não como uma soma, porém, prescreve o modo-de-ser da cotidianidade ${ }^{8}$.

Nossos gostos, nossos gozos, nossas opiniões, tudo é determinado por a-gente. Eis a vida quotidiana: a vida de ninguém e de todos; a vida que todos vivemos, sem que nenhum de nós seja alguém. Havendo apenas a-gente, nunca há o eu, tampouco o tu, de modo que também o nós fica restrito a um pronome da formalidade. No português brasileiro, o império de a-gente se evidencia também na fala quotidiana. No medo de me colocar em perigo de debate, no medo de me expor, coloco como sujeito de minhas opiniões a-gente: "a gente sabe que esse governo não presta", "a gente fica com medo em uma situação dessas, né?", "a gente tende a usar a gente o tempo todo", "a gente sempre procura o melhor pros nossos filhos". Não sou eu que penso que o governo não presta, não somos nós que ficamos com medo, não é você que procura o melhor para seu filho. A gente tende, na verdade, a viver na impessoalidade.

0 isolamento físico imposto pela pandemia alterou o quotidiano de todos ao retirar de nossa vida a rotina, caráter essencial do quotidiano, impactando, assim, o modo de ser $a$ gente. Nesse cenário, como fica a-gente? Muitas são as respostas corretas. Como havia dito, são tão diversas as realidades a cada um de nós impostas que oferecer uma resposta definitiva e certeira é impossível. Parece evidente, contudo, que a supremacia de a-gente nunca acabará, assim como que sempre existiu. Em um mundo cada vez mais cheio, industrializado, globalizado e técnico, a-gente consolida sua onipotência. Todavia, hoje, as ruas estão vazias, as

\footnotetext{
${ }^{6}$ Ver ST, § 27.

7 Em alemão, há, além do feminino e do masculino, o gênero neutro, representado, aqui, pelo artigo definido das. Como em português não temos esse gênero, não usarei qualquer artigo para me referir à palavra "a-gente".

Sobre a tradução: segui a opção adotada por Fausto Castilho. Man é equivalente à nossa partícula apassivadora $s e$, por exemplo em "Vive-se na inautenticidade". Em alemão, como sempre é necessária a existência de um sujeito, usa-se o Man - equivalente ao one no inglês. Assim, na frase "vive-se na inautenticidade", o sujeito, em alemão, seria o Man; em português, o se faz o papel de sujeito indeterminado. Na língua falada, trocamos o "vive-se" por "a gente vive". Destarte, ao me referir a $a$ gente, tenho em mente o sujeito indeterminado que somos no modo de a-gente.

8 ST, § 27, 365. "Wir genießen und vergnügen uns, wie man genießt; wir lesen, sehen und urteilen über Literatur und Kunst, wie man sieht und urteilt; wir ziehen uns aber auch vom "großen Haufen« zurück, wie man sich zurückzieht; wir finden »empörend«, was man empörend findet. Das Man, das kein bestimmtes ist und das Alle, obzwar nicht als Summe, sind, schreibt die Seinsart der Alltäglichkeit vor". SZ, 169 [127].
} 
indústrias quietas, as viagens suspensas, os negócios congelados, e, o mais inédito, alguns de nós com ócio, e todos com espanto ${ }^{9}$. As condições materiais mais evidentes para a hegemonia de a-gente foram suspensas. É nesse momento que o tédio e a angústia, humores essenciais, ficam mais presentes em nossa sociedade. Haveria aqui um momento propício para a reflexão individual? Parece que sim. A pandemia nos obrigou a colocar entre parênteses nossa vida, a suspendê-la enquanto a rotina não retorna. Muitos agora estão com a oportunidade de verem a si mesmos, de se sentirem, de olharem para o próprio desejo, para o próprio eu. É momento de dar atenção. Presos em casa, tentamos fugir em direção a a-gente, sempre. Buscamos na internet e na televisão o gosto da vida inautêntica, anônima. Nunca o BBB teve tanto expectador. Mas isso não é suficiente. Ora ou outra, muitos acabam tendo que se encarar. Sem saber o que fazer, cansado das mesmas idiotices de sempre, olho para o teto, sou atacado pelo tédio, e percebo que sou! Percebo que existo, percebo que tenho gostos próprios, sinto meu desejo, sinto meus afetos, sinto que não sou apenas a-gente. Olho para mim, me encaro e descubro que sou possibilidades, que odeio meio trabalho, que amo minha namorada, que não aguento meu colega de quarto, que sinto falta de minha família. Percebo que não precisava mais estar aqui, que poderia me mudar desta casa horrível, que poderia sair desta empresa, investir mais em minha educação, enfim, percebo minhas possibilidades e percebo que eu as sou. Nesse momento, deixo de ser apenas a-gente e passo a ser mim-mesmo, deixo de ter exigências de a-gente e passo a exigir de mim. Agora que começo a me olhar, começo a me construir como singularidade livre em meio a a-gente, sou capaz de dar atenção à singularidade. Retomemos o trecho inicial de Heidegger: Dou atenção àquilo que exijo de mim e, exigindo, sou.

Em uma palavra, isolado consigo dar atenção a mim. Dar atenção a mim implicará duas coisas: uma análise de mim e um cuidado de mim. Comecemos pela primeira.

\section{Isolamento e atenção a si mesmo}

Encaro-me como ser com desejos próprios, como singularidade. Percebo o esquecido eu soterrado. A primeira característica minha já foi percebida: sou possibilidades. Não irá espantar ver diversas pessoas mais conscientes dos próprios desejos e projetos ${ }^{10}$ ao final da pandemia, ao menos pessoas mais conscientes da própria insatisfação ou pessoas com novos objetivos e projetos de vida. De todas as possibilidades de nossa vida, contudo, impor-se-á com maior força a única da qual nunca conseguiremos escapar: a morte. Heidegger nos caracteriza como seres-para-a-morte: os únicos mortais que sabem da própria morte. Tentamos sempre nos esquecer de nossa finitude, mas nunca conseguimos. Agora, parece mesmo impossível. Percebemos - e isto é o que mais dói! - nossa impotência ante a inexorável morte. Presos em casa, sofrendo a morte de familiares, amigos, conhecidos, ou mesmo de desconhecidos, impõe-se-nos o fato de que, em meio a todas as nossas possibilidades, está sempre a possibilidade de não mais ser. Esta, contudo, nunca pode ser vista por mim: trata-se da única possibilidade certa e da única possibilidade da qual apenas tenho conhecimento a partir de sua realização nos outros, isto é, da morte dos outros. Diante desse fato, podemos finalmente ver o lado positivo de nosso latente não ser: "A morte não 'pertence' só indiferentemente ao Dasein ${ }^{11}$ próprio, mas ela o interpela como singular. A irrelatividade da

\footnotetext{
${ }^{9}$ Lembremos que os gregos encaravam o espanto como o humor fundamental para o início do caminho filosófico.

${ }^{10}$ Sigo aqui o conceito sartreano de projeto.

11 Termo que Heidegger usa para se referir à realidade humana (ao humano). Literalmente: ser-aí.
} 
morte, entendida no adiantar-se, isola o Dasein em si mesmo"12. Ao encarar a certeza da minha morte, minha inelutável finitude, eu me singularizo. Nesse momento, me afasto de a-gente, percebo-me como singular. Impelido para minha singularidade, tomo consciência de toda a minha existência - que sou um ser temporal, tenho passado, vivo o presente e sou projetado para um futuro - e assumo, conforme palavras do professor Marco Werle, minha própria "existência, já que a experiência da morte é sempre apenas minha"13. Em outras palavras, ao me encarar como ser-para-a-morte, ao constatar que todas as minhas possibilidades são assombradas pela possibilidade de não ser mais, apreendo-me como eu, como destacado da totalidade, como detentor de uma singularidade, uma individualidade, portanto, como desvinculado de a-gente.

0 homem que tem a visão de sua vida devido à aproximação da morte nunca mais será o mesmo: a voz da finitude sempre continuará sussurrando ao seu ouvido. Podemos aqui nos lembrar do caso dos países em guerra e do impacto que a visão da morte tem sobre os indivíduos. A diferença maior, creio, entre uma pandemia e uma guerra é a inexistência, no primeiro caso, de um culpado. Após a guerra, sempre permanecem o ódio, o medo, a vergonha. Após a pandemia, não restará ódio a um grupo, a um país, pois não há nem pode haver um culpado ${ }^{14}$. Restarão apenas vítimas. Teremos a oportunidade, enquanto sociedade global, de unirmo-nos mais, solidarizarmo-nos com todos; enquanto indivíduos, olharemos apenas para nós mesmos, por não termos onde mais olhar.

\section{0 cuidado de si: ocupação e preocupação}

Olhando para mim, dou atenção a mim, portanto, cuido de mim. Heidegger caracterizará, em ST, o humano (Dasein) como o único ente que cuida de seu próprio ser. Descobrindo que somos seres-para-a-morte, descobriremos também que somos cuidado: cuidamos de nós e de tudo à nossa volta. Ao falar que somos cuidado, Heidegger quer dizer: nós necessariamente cuidamos; só podemos descuidar - deixar de cuidar - por, essencialmente, cuidarmos. No modo de a-gente, engolidos pela uniformidade, temos também nosso cuidar determinado pelo modo de cuidar de a-gente, o qual visa ao nivelamento de todas as possibilidades e ao imediato. Aqui devemos nos lembrar da alegoria da caverna platônica ${ }^{15}$. Preso no modo de a-gente está aquele prisioneiro acorrentado, para quem a realidade é o que imediatamente aparece à sua frente, quem desconhece a existência de passado e futuro, bem como de outras possibilidades que não aquelas apresentadas incontinenti. Preso, assim, a essas possibilidades, como vimos acima, o homem no modo de agente é uniformizado: suas possibilidades, gostos, desejos, projetos são nivelados. Qualquer eu é sufocado em nome do rebanho. Em outros termos, aquele que olha para si no modo de agente não consegue ter um conhecimento verdadeiro das próprias possibilidades. 0 cuidado do quotidiano, portanto, é um cuidado superficial, que nos faz olhar para nós mesmos como meros animais de rebanho ${ }^{16}$, negligenciando, pois, nosso próprio ser. Esse cuidado é o mesmo que temos em relação aos entes que nos cercam. 0 cuidado que tenho com o prato em que como é o cuidado que entende este objeto como útil, procura apenas por sua possibilidade mais imediata - a de sustentar o alimento - e trata este objeto em específico como trataria

\footnotetext{
12 ST, § 53, 723. “Der Tod 'gehört' nicht indifferent nur dem eigenen Dasein zu, sondern er beansprucht dieses als einzelnes. Die im Vorlaufen verstandene Unbezüglichkeit des Todes vereinzelt das Dasein auf es selbst." SZ, 263.

13 WERLE, A Angústia, o Nada e a Morte em Heidegger, 111.

${ }^{14}$ Haverá - e é o caso do presidente brasileiro - sim um culpado por não tomar as medidas necessárias para a contenção da pandemia, mas nunca haverá um culpado pela existência da pandemia.

15 PLATÃo, A República, 38a.

${ }^{16}$ Expressão de Nietzsche, utilizada, em especial, em Além do Bem e do Mal e em Genealogia da Moral.
} 
qualquer outro objeto parecido. A esse cuidado, Heidegger chama ocupação [Besorgen]. Ocupamo-nos de nós mesmos como ocupamo-nos dos instrumentos que nos cercam. Vemos nós mesmos como instrumentos de a-gente. Lembremos agora a última frase do trecho com que iniciamos nosso ensaio: "E unicamente a profundidade na qual eu posso exigir, de mim mesmo, o meu ser decide sobre meu ser para os outros". Difícil construção, que poderia ser lida como: o modo por que cuidamos de nosso ser é o mesmo por que cuidaremos do ser do outro. Na quotidianidade, nós nos ocupamos de nós, portanto nos ocupamos também dos outros. Nossa relação com o outro é de mera utilidade: até mesmo os laços afetivos que construímos são fundados na utilidade que o outro pode nos proporcionar, por isso, como conclui Sartre, são todos eles fadados ao fracasso ${ }^{17}$.

Se nossa tese aqui é a de que, com a pandemia de Covid-19 e o isolamento físico forçado, alguns de nós terão possibilidades materiais facilitadoras da libertação do modo de agente, queremos dizer também que a modalidade de cuidado empregada por nós poderá ser alterada. Entregues a nós mesmos, damos atenção ao nosso ser, o qual são nossas possibilidades (eu sou minhas possibilidades). Descobrimos, aí, que somos seres-para-amorte, bem como que somos cuidado e somos-com-os-outros. Assim, podemos alterar nosso modo de cuidado tanto para com nós mesmos quanto para com o outro: da ocupação passaremos para a preocupação [Fürsorgen]. Este modo de cuidar não busca a utilidade daquilo de que se cuida. Dando atenção a mim, primeiramente preocupar-me-ei comigo: verme-ei como possibilidades, como individualidade; preocupando-me comigo, poderei preocupar-me também com o outro. Ora, se da minha preocupação comigo resultou a constatação de que sou minhas possibilidades, da minha preocupação com o outro, o qual é análogo a mim, resultará a mesma constatação. Com isso, verei que o outro é necessariamente livre, agirei para que o outro também se veja como liberdade e, por fim, zelarei para que o outro continue em sua liberdade. Em uma palavra, sendo autêntico, poderei exigir do outro sua autenticidade, de modo que nos tornaremos cúmplices.

Tomo o conceito de cumplicidade como apresentado por Sartre18: cúmplice é aquele que me ajuda a dirigir-me a minhas próprias possibilidades, que abre possibilidades e que me revela para mim mesmo como liberdade. Liberdade deve ser entendida tanto no sentido ontológico quanto no sentido prático. "Ontologicamente, sou liberdade”, isso quer dizer: nada me define. Sou no modo de não ser, diria Sartre, ou sou sempre adiantado-em-relação-a-mim, diria Heidegger. Diferente dos outros entes, não dou definido por uma essência anterior, a qual oferece as características fundamentais de meu ser. Sou negação de meu presente, (re)significação de meu passado e projeção para meu futuro. Sou minhas possibilidades, meu poder-ser, isto é, sou livre. No sentido prático, liberdade se refere, na tradição, à ausência de empecilhos para a realização de determinada ação. Liberdade prática é o poder-fazer, enquanto a ontológica, o poder-ser. 0 cuidado comigo abre-me para ambas as liberdades: primeiramente, aceito-me como necessariamente livre, aceito minha indeterminação ontológica; por conseguinte, constato minha total responsabilidade em relação a tudo o que me toca. Depois, vejo as possibilidades de ação que a situação em que estou oferece e, então, percebo-me também responsável por todas as minhas escolhas. Esta é a vida autêntica: a vida que se aceita como livre e que assume totalmente a situação em que vive, uma vez que, para que eu possa verdadeiramente ver as possibilidades de ação que a situação me oferece, preciso, antes de tudo, aceitar-me como participante desta situação. Em nosso caso, poderíamos dizer: a preocupação faz-me aceitar minha indeterminação, minha liberdade necessária e, portanto, minha responsabilidade absoluta. Com isso, aceito, também, minha situação: estou numa pandemia, estou isolado, estou rodeado de mortes. Aceitando minha situação, aceito-me como responsável por todas as minhas escolhas (aceitar ou não a

\footnotetext{
17 O Ser e o Nada, III, III, I.

18 SARTRE, Cahiers, 291e ss.
} 
quarentena e o distanciamento, aceitar ou não ser desta etnia, aceitar ou não ter esta orientação sexual, aceitar ou não ter esta história). Se aceito minha situação, abro espaço para a realização de minhas possibilidades, aceito-me como podendo-ser e podendo-fazer e, assim, renego o modo de ser de a-gente. Portanto, mesmo em uma aparente contradição, a pandemia, ao isolar-nos, isto é, ao retirar muito de nosso poder-fazer, estendeu as condições para nos percebermos como poder-ser responsável por todo poder-fazer. Se antes nos notávamos apenas como podendo-fazer muita coisa, hoje podemos nos notar como podendo-ser nós mesmos.

\section{Conclusão}

Como disse acima, não defendo de modo algum que essa realidade é a da maioria hoje. Seria por demais utópico e até mesmo insensível de minha parte. Sabemos que a violência doméstica aumentou, e muito, após o confinamento (estima-se, hoje, que no Rio de Janeiro o aumento foi de 50\%, enquanto em São Paulo de $30 \%$, para ficarmos com dois exemplos brasileiros ${ }^{19}$ ). A violência tem fundamento no modo de ser da ocupação: apenas posso violentar aquele que vejo como um instrumento de meus desejos, equiparado à roupa que uso. 0 confinamento também oferece as condições materiais para que minhas relações de instrumentalidade sejam restritas a uma menor quantidade de pessoas, quais sejam, aqueles que vivem comigo. A mim me parece, contudo, que o confinamento não estimula o modo de ser da ocupação, isto é, não faz com que uma relação que antes era de preocupação se torne de ocupação. A violência aumenta - como é triste dizê-lo - pois tenho mais tempo para exercer faticamente minha relação de instrumentalidade: estou mais tempo com aquele que considero meu instrumento (e só posso descontar minhas frustrações naquilo que vejo como instrumento). Destarte, ser obrigado a conviver mais com alguém me dá tempo ou para continuar vivendo aquele tipo de relacionamento que eu já tinha, ou para construir um novo tipo de relação. Contudo, essa mudança apenas ocorrerá, como defendemos antes, se houver antes uma mudança em relação a si mesmo. Se passo a dar atenção a mim, ver-me-ei como ser-com-o-outro e ser-para-o-outro, como aquele que apenas é com o outro. Ora, o outro é aquele que se assemelha a mim. Se dou atenção a mim, percebo-me como ser, não como instrumento de a-gente, portanto verei o outro necessariamente também como ser, não como meu instrumento. Ter de ficar confinado aumenta para mim a possibilidade de cuidar autenticamente de mim e do outro, ao mesmo tempo, é claro, que mantém aberta (pois sempre esteve aberta) a possibilidade de continuar na ocupação tanto de mim quanto do outro.

Gostaria de oferecer mais uma defesa contra uma possível acusação de elitismo. Sartre, em um momento, a meu ver, de grande lucidez e razoabilidade, afirmou, acerca dos judeus que lutavam por continuarem vivos em meio ao nazismo:

Eu diria de bom grado que a inquietação metafísica é um luxo que o judeu, tal como o operário, não pode permitir-se hoje. É preciso estar seguro de seus direitos e profundamente arraigado no mundo, é preciso não nutrir quaisquer dos temores que assaltam diàriamente as classes ou as minorias oprimidas, para tomar a liberdade de interrogar-se sobre o lugar do homem no mundo e sobre seu destino. Numa palavra, a metafísica é apanágio das classes dirigentes arianas. Que ninguém veja nestas observações uma tentativa de

${ }^{19} \mathrm{https}$ ///www12.senado.leg.br/noticias/audios/2020/04/aumento-da-violencia-domestica-noisolamento-social-preocupa-senadores 
desacreditá-la: ela virá a ser a preocupação essencial do homem quando os homens se libertarem. A inquietação do judeu não é metafísica, mas social20.

Aqueles que lutam para sobreviver não têm o luxo de terem questões metafísicas. Para as ter, antes é necessário o mínimo social. Como pensar tudo o que aqui disse sendo que a pandemia aumentou assustadoramente a quantidade de miseráveis, de famintos, de desempregados? Meu ponto central o tempo todo foi que a pandemia oferecia condições materiais para uma vida mais autêntica. Contudo, em nenhum momento defendi que essas condições foram dadas a todos. Assim como há o desempregado, há aquele que está trabalhando doze, catorze, dezesseis horas por dia dentro de sua casa ou pedalando para entregar almoços. Principalmente para esses com trabalho quase de escravo, qualquer preocupação que não social parece secundária. É preciso, claro, antes garantir-lhes o mínimo para que possam olhar para eles não mais como instrumentos, mas como humanos. Aquele que trabalha dia e noite e mal consegue colocar comida na mesa, o miserável, o faminto: não lhes é permitido olhar para si a não ser como instrumentos da própria sobrevivência. Ao Estado cabe garantir-lhes o mínimo para serem humanos. Mas não é esse o assunto deste ensaio. 0 tempo todo referi-me a algumas pessoas. Por outro lado, aproveito o trecho de Sartre para defender que a preocupação não é uma inquietação metafísica, portanto, que não é um luxo, de modo que a abrangência de minha reflexão se expande.

É verdade que não me referi aos grupos mais vulneráveis neste artigo, mas também não me referi apenas a uma classe mais abastada. Preocupar-me comigo, dar atenção a mim condição inicial de toda nossa argumentação - não se trata de uma inquietação metafísica que exigiria de mim um estudo avançado, tampouco longo tempo de meditação. Trata-se de um modo essencial de cuidado assim como a ocupação. Um ataque à saúde na magnitude de uma pandemia implacável como a de Covid-19 me parece exigir um cuidado constante de mim e dos outros. A cada tosse me vigio; a cada vez que meu irmão sai de casa, me preocupo com ele. Meu olhar necessário a mim e a ele é o primeiro passo para uma atenção a mim como um todo, não apenas a uma parte de mim.

Pela primeira vez em muito tempo, talvez em toda a minha vida, não posso pensar apenas em meu trabalho, em meus estudos, em meu almoço, em minha casa. Urge colocar a saúde minha e de todos ao meu redor em primeiro plano, mesmo que nenhum de nós esteja doente. Não devo cuidar de uma doença que acomete a mim ou a meu irmão, mas devo cuidar de minha saúde que se encontra boa. Quero dizer com isso: minha atenção não está na doença, mas na minha existência.

A humanidade começa o século XXI com uma pausa no mundo da técnica e da utilidade. Líderes mundiais da nova extrema direita colocam ainda o desenvolvimento técnico-utilitário acima de tudo. Enquanto isso, nós, homens e mulheres comuns, já demos o primeiro passo para a saída do século XX, para, portanto, o descontentamento em relação a esses líderes nefastos. Em nível social, um impacto positivo desse tamanho parece utópico; em nível pessoal, contudo, vidas livres e autênticas parecem mais próximas.

\section{Referências}

ARENDT, H. Briefe 1925 bis 1975: und andere Zeugnisse. Frankfurt am Main: Vittorio Klostermann, 2002.

HEIDEGGER, M. A teoria platônica da verdade. In: HEIDEGGER, M. Marcas do caminho. Tradução de rev. da trad. Marco Antonio Casanova Enio Paulo Giachini e Ernildo Stein. Petrópolis, RJ: Vozes, 2008. p. 215-250.

${ }^{20}$ SARTRE, Reflexões sobre a questão judaica, 77. 
HEIDEGGER, M. Nietzsche II. Tradução de Marco Antonio Casanova. Rio de Janeiro: Editora Forense, 2007.

HEIDEGGER, M. Ser e Tempo. Tradução de Fausto Castilho. Campinas, SP; Petrópolis, RJ: Unicamp; Vozes, 2012. edição bilíngue.

HEIDEGGER, M. Serenidade. Tradução de Maria Madalena Andrade e Olga Santos. Lisboa: Instituto Piaget, 20 ?.

NIETZSCHE, F. Além do bem e do mal. Tradução de Renato Zwick e apresentação de Marcelo Backes. Porto Alegre - RS: L\&PM Pocket, 2014.

SARTRE, J.-P. Cahiers por une morale. Paris : Gallimard, 1983.

SARTRE, J.-P. O Ser e o Nada: Ensaio de Ontologia Fenomenológica. Tradução de Paulo Perdigão. 24. ed. Petrópolis, RJ: Vozes, 2015.

SARTRE, J.-P. Reflexões sôbre a questão judaica. In: SARTRE, J.-P. Reflexões sôbre o racismo. Tradução de J. Guinsburg. São Paulo: Difusão Europeia do Livro, 1968.

WERLE, M. A. A Angústia, o Nada e a Morte em Heidegger. Trans/Form/Ação, São Paulo, v. 26, p. 97-113. 